\title{
Sufficiency and the Threshold Question
}

\author{
Robert Huseby ${ }^{1}$ (D)
}

Received: 2 July 2018 / Accepted: 7 January 2020 / Published online: 27 March 2020

(C) The Author(s) 2020

\begin{abstract}
In this paper I address the objection to sufficientarianism posed by Paula Casal and Richard Arneson, that it is hard to conceive of a sufficiency threshold such that distribution is highly important just below it, and not required at all just above it. In order to address this objection, I elaborate on the idea that sufficientarianism structurally can be seen to require two separate thresholds, which may or may not overlap. I then argue that a version of such a view is plausible. Lastly, I distinguish this view from related proposals in the literature.
\end{abstract}

Keywords Distributive justice $\cdot$ Negative thesis $\cdot$ Positive thesis .

Sufficientarianism $\cdot$ Thresholds

\section{Introduction}

In my view, the basic sufficientarian intuition is simple, if vague: people ought to have good lives, and it is bad whenever they do not. ${ }^{1}$ A main challenge is to cash out 'good' with regards to where the threshold is set. Other important challenges include defending the further (and implicit) claims that it does not matter that individuals are equally well off, and that we do not need to prioritize the worst off, so long as they are sufficiently well off, and that whatever makes lives good, for instance utility or well-being, is not worth maximizing.

The idea that it is morally important that people have enough is often referred to as the 'positive' sufficiency-thesis, while the idea that further distribution is not required once everyone has enough, is referred to as the 'negative' sufficiency-thesis. ${ }^{2}$ These two theses and the relation between

\footnotetext{
${ }^{1}$ Sufficientarianism comes in many versions. See Anderson (1999), Axelsen and Nielsen (2015), Benbaji (2005, 2006), Crisp (2003), Frankfurt (1987), Huseby (2010), Orr (2005) and Shields (2012, 2016).

2 These labels are due to Casal (2007: 297-300). Notice that it is perfectly possible to affirm the positive, and reject the negative thesis (Shields 2012, 2016). Many sufficientarians, however, accept both theses.

Robert Huseby

roberthu@stv.uio.no

1 Department of Political Science, University of Oslo, Oslo, Norway
} 
them are, however, ambiguous and open to interpretation in some important ways. $^{3}$

My aim here is to address one particularly incisive criticism concerning the justification and specification of sufficientarianism. ${ }^{4}$ The criticism, which I refer to as the threshold objection, pressed in particular by Paula Casal and Richard Arneson, holds that it is hard to conceive of a sufficiency threshold such that distribution is highly important just below it, and not required at all just above it (Arneson 2005; Casal 2007). This is a severe challenge. In order to address it, I start with a suggestion offered by Casal, and develop the idea that sufficientarianism can structurally be seen to require two separate thresholds, which may or may not coincide (Casal 2007: $317)$. I then argue that some version of this view is indeed plausible. Such a view would disarm the threshold objection, insofar as the two thresholds can be independently justified. The result would be a strengthened case for sufficientarianism.

In the next section, I first argue that both the positive and the negative theses are plausible in their own right, and then explain Casal's and Arneson's criticism in some more detail. Section 3 develops the idea that the two theses might refer to different thresholds, while Sect. 4 specifies further my preferred version of such a view, including the different questions concerning how to distribute below, above and between the thresholds. The penultimate section briefly explains how my proposed view relates to other sufficientarian accounts in the literature, and the last section concludes.

\section{The Positive and Negative Theses and the Threshold Question}

Even though sufficientarianism has been subject to substantial criticism, the positive thesis, in some version, is commonly (though of course not universally) accepted. Many agree that it is morally important that people have lives of some minimum quality. It sounds intuitively wrong to say that it does not matter at all, from a moral point of view, whether people are sufficiently well off or not. Faced with people in need, we do not merely think that it is bad that the deprived are worse off than others, or merely that it would be better to benefit them than the slightly less deprived. We also think that it is just bad that the deprived have as little as they do, and that this provides moral grounds for redistribution. ${ }^{5}$ Indeed, the arguably most influential critic of sufficientarianism, Paula Casal, claims that most views accept some version

\footnotetext{
${ }^{3}$ Note that I am concerned with morally important claims that give rise to just claims for distribution. Not all morally important claims are justice claims, however. For example, as I will argue below, some claims (from the worse off) can sometimes have absolute priority over other claims (from the very well off). The latter claims, then, do not give rise to just clams for distribution, but they might nevertheless be morally important, to varying degrees..

4 Many other questions, criticisms and clarifications are addressed elsewhere. See Axelsen and Nielsen (2015), Benbaji (2005, 2006), Casal (2007), Crisp (2003), Frankfurt (1987), Holtug (2010), Huseby (2010, 2012), Nielsen (2016), Segall (2016) and Shields (2012).

5 This intuitive idea has been invoked by many sufficientarians. See for instance Frankfurt (1987: 32). See also Raz (1986). Note that for deprivation to ground distributive claims, it must be the case that some others have sufficient resources to provide assistance without themselves becoming deprived.
} 
of the positive thesis (Casal 2007: 299). See also Axelsen and Nielsen (2015: 407), Huseby (2019). This is not to suggest that most people accept some form of fullblown sufficiency, or that they agree about where exactly the threshold is located. It is just to suggest that sufficiency, or at least the aspect of sufficiency associated with the positive thesis, is very plausible, and that many seem to agree.

In my view, more specifically, it is especially morally important that people have good lives. There will of course be disagreement about what a good life is. I will here state my view briefly, since the aim of this paper is not primarily to provide an account of what constitutes a good life. It seems, moreover that we can have a plausible intuitive idea about what a good life is like, even if we do not agree on all the specifics.

A good life, as I conceive of it, consists of both objective and subjective elements, on two levels. First, a good life contains a certain amount of subjectively experienced well-being, as well as a certain amount of objective qualities (love, friendship, meaningful projects, some level of flourishing etc.). This is reminiscent of Dworkin's distinction between volitional and critical well-being. It is not identical, however, because on Dworkin's view, the volitional and critical elements do not track the subjective and objective distinction. In addition, the volitional aspect concerns desire-satisfaction rather than subjectively experienced well-being (Dworkin 2000: 242). It is nevertheless clear that Dworkin (2000: 243) too aims to capture both aspects of well-being that are subjectively good for the person (volitional) and aspects that are objectively good for the person. ${ }^{6}$ This is reasonable, since both these aspects seem to be necessary for a good life. It is hard to see how a life can be good if it either completely lacks subjective experience of well-being, or completely lacks the things that are objectively valuable.

Second, for a person to have a good life, she must herself evaluate her life as good, and do so with good reason. Thus, she should actually be content with her life, because one's life is not reasonably seen as good if one is discontent with it. Further, one's reasons for being content should be plausible in an objective sense. This means that one's life can be insufficiently good, even if one is content with it, if one is content for the wrong reasons, for instance because one is manipulated or deceived, or if one is subject to unduly adaptive preferences. Again, this brief gesturing is not intended as anything like a theory of what a good life is. It is just to point to some relevant features, and to broadly suggest one possible view of a good life. The arguments in this paper are compatible with a variety of views on what a good life consists in. ${ }^{7}$

The concept of a good life, however understood, is interesting from a sufficientarian point of view, and I think it is well suited to explicate the positive threshold. First, it seems intuitively morally important that people have good lives. (As an exercise, try telling yourself otherwise). Regardless of one's exact understanding of

\footnotetext{
${ }^{6}$ See moreover Dworkin (2000) ch. 6 for a very interesting discussion of many of the complexities associated with different aspects of well-being. See also Hupfer (2019), for a related discussion.

7 I think it is possible to interpret at least Crisp's (2003) and Frankfurt's (1987) accounts as attempts to tie the sufficiency threshold to some notion of good lives. See also Huseby (2010).
} 
what a good life is, it is bad if someone's life is not good. This sounds almost selfevident, and bears emphasizing. If we come across a person whose life is not good, this naturally strikes us as bad, and something that ought to be corrected. In addition, it seems that a good life is something of a threshold question, because it is not bad, or so I claim, that someone is not in a state of eternal bliss, and even not bad that someone is less well off than she could have been, so long as her life is good.

Consider how we relate to ourselves and others. I assume that it matters to most people that their children's lives are good, and that their friends' lives are good. And clearly it is bad if one's children or friends have lives that are less than good. But many people would not think it bad as such that their children or friends were not in a state of eternal bliss, or even that they had lives that were less good than they possibly could be (which is not to say that it cannot be better, personally or impersonally, that one's children or friends have lives that are even better than good). Moreover, I think this is the way many people also see their own lives, as well as the lives of strangers. Thus, even when we contemplate the well-being of more or less distant others, it seems that it is morally important that their lives are good, and morally bad if their lives are less than good. ${ }^{8}$

It is also worth noting that, even though many writers find sufficientarianism unpersuasive in the end, the reasons they cite do not usually question the impersonal value of sufficiency as such. ${ }^{9}$ Rather, the critics tend to question the claim that no further distributive principles apply (above the threshold). ${ }^{10}$ Or, as noted, they question the possibility of defining a threshold that is able to carry the weight of both the positive and the negative theses. ${ }^{11}$ Few critics, to my knowledge, object to sufficientarianism because it is implausible to be concerned with whether or not people have sufficiently good lives, or because absolute deprivation, in itself, is morally irrelevant. ${ }^{12}$ It appears then, that we have reason to believe (in addition to whatever else we may believe) that there is a level of well-being, that is such that it is especially morally important that individuals reach it.

What about the negative thesis? As Crisp (2003) and others have pointed out, at some level of well-being, distributive concerns tend to peter out. At the very least, many do not care, from the point of view of justice, that two extremely well off individuals are not exactly equally well off. Again, this is controversial, and arguably more so than the positive thesis. Prioritarians and egalitarians, for instance, disagree wholeheartedly.

\footnotetext{
${ }^{8}$ This is not to suggest that most people are equally concerned with strangers as with their own children and friends.

9 See Segall (2016) for a possible exception.

10 That is, Casal's negative thesis.

11 It is also possible to question the possibility of defining a good life, since well-being comes in degrees. It seems though, that it is quite common and unproblematic to say that a life can be good or bad. In this paper I do not address this objection further.

12 Depending on where the (positive) threshold is set, insufficiency need not always imply deprivation in an ordinary sense. See Huseby (2019).
} 
There are, however, at least two ways of understanding the negative thesis, that are sometimes run together. ${ }^{13}$ On one view, the negative thesis defines the threshold at which further distributive principles cease to apply. Supposing everyone is above this threshold, differences among people are of no concern from the point of view of justice. I happen to share this view, but it does not seem very important. Imagine that everyone is fantastically well off, and some are a tiny bit better off than the others. If so, egalitarians and many prioritarians would require redistribution, while defenders of the negative thesis would not. But very little would arguably be at stake, at least from a sufficientarian point of view. It is not as if equality among the extremely well off is in any way morally offensive. It is just that for those who accept the negative thesis, there does not appear to be any positive reasons in favor of redistribution at very high levels. For egalitarians and prioritarians, however, there are such reasons. ${ }^{14}$

On the second view, which I think is more important, the negative thesis defines the threshold at which well-being ceases to matter morally in distributive conflicts between those above and below that threshold. In other words, the negative thesis marks the point at which those below it have absolute priority over those above it. ${ }^{15}$ Here, more is at stake. Unless we introduce absolute priority at some point, we have to accept that mild pleasures for many extremely well off people can outweigh excruciating pain for one extremely badly off person. ${ }^{16}$ In my view this is clearly implausible, and implies that absolute priority is required at some point. ${ }^{17}$

It is worth noting that the negative thesis is supported by limitarianism, the view that it is "... not morally permissible to have more resources than are needed to fully flourishing in life (Robeyns 2015: 2)." This view is even stronger than the (second version of the) negative thesis, since it not only gives absolute priority to those below the threshold, but actually bans the holding of resources above it. Though there are clear affinities between limitarianism and sufficientarianism, Robeyns' particular version of limitarianism is explicitly non-ideal and resource-oriented, which

\footnotetext{
13 Note that the negative thesis, in so far as it pertains to egalitarianism, prioritarianism, and utilitarianism, may be based simply on the rejection of these principles. There are serious objections to all three, and if one accepts these objections, the negative thesis is implicitly and negatively (and partially) justified.

14 For many prioritarians, the reasons for redistribution at very high levels become weaker and weaker, because it is less and less important to benefit people, the better off they are. At least some egalitarians, on the other hand, would think that equality is equally offensive regardless of how well off the parties are in absolute terms.

15 It might seem that this idea is quite similar to the positive thesis. After all, if it is especially important that people have good lives, one might think that those who do not have good lives should have absolute priority over those who do have good lives. It is perfectly possible, however, and in my view plausible, to keep the two apart. To say that something is important, is not to say that it overrides all other concerns. I return to this below.

16 See Arneson (2005). Note that this is a problem for prioritarianism, but not egalitarianism.

17 Note that these two versions of the negative thesis are not logically connected. One could give absolute priority to those below the threshold, while at the same time apply prioritarianism or egalitarianism above it. One could also deny any distributive principles above the threshold, without giving absolute priority to those below. I assume, however, that most defenders of the negative accept both versions.
} 
makes a direct comparison between the two a bit difficult. But the support of the negative thesis is still worth taking into account. ${ }^{18}$

As is well known, absolute priority is not without costs. Absolute priority means that all well-being for those above the threshold can be sacrificed for the sake of however small gains for those below the threshold. In addition, problematic aggregation can still occur below the threshold (I return to this below). There are many hard questions concerning the trade-off between aggregation and absolute priority, and the negative threshold does not solve all of them. However, a negative threshold at or above the level of a good life does close off the extremes. First, it denies limitless aggregation as utilitarianism and many forms of prioritarianism imply. Second, it denies absolute priority to the worst off (or just the badly off) as leximin versions of prioritarianism imply.

So, in my view there are strong reasons to accept both the positive and the negative theses; first, it is especially morally important that people have good lives, and bad if they do not. Second, it is plausible that there is a level of well-being such that above it, further distributive principles do not apply, and surplus well-being does not count in trade-offs involving people whose well-being is below it. ${ }^{19}$ Nevertheless, it is, as Casal and Arneson have insisted, hard to imagine a threshold low enough to make plausible the positive thesis, and high enough to make plausible the negative thesis. According to Casal,

...lower thresholds make it more plausible to insist, as the positive thesis does, that everyone must have enough, but less plausible to endorse the negative thesis's dismissal of egalitarian and prioritarian considerations when resolving distributive conflicts between those who have plenty and those who have barely enough. ${ }^{20}$

Conversely, higher thresholds might make the negative thesis more plausible because many, as noted, care less about well-being and well-being inequalities at high or very high levels. However, this comes at the cost of undermining the credibility of the positive thesis, because it is harder to argue that it is particularly morally urgent that everyone becomes (nearly) fantastically well off. The two theses, though arguably plausible in themselves, tend to pull the sufficientarian threshold in two different directions, and it admittedly seems odd that there is a threshold that is such that it is of paramount importance that peoples reach it, and such that distribution

\footnotetext{
18 It would be interesting, as Robeyns suggests, to work out ideal (and perhaps welfare-oriented) versions of limitarianism. This would be enlightening in itself, but it would also help clarify the relationship between limitarianism and (ideal, welfare-oriented) sufficientarianism.

19 Notice that more complicated views are available. One could argue that there are several negative theses defined in terms of the distance to the worse off. Thus, in conflicts between the very well off and the badly off, the surplus well-being of the very well off does not count. However, in conflicts between the very well off and the nearly very well off, the surplus well-being of the very well off counts for something. While not implausible, I will not address such views here.

${ }^{20}$ For a similar line of argument, see Arneson (2005). Notice that the objection is reasonably seen to encompass both versions of the negative thesis, even if this is not explicit in Casal's (2007: 315) criticism. It seems at least that absolute priority is less plausible the lower the level at which it is applied.
} 
just above does not matter at all, and such that those below it has absolute priority over those above it.

\section{Two Theses-Two Thresholds}

In the following, I will elaborate on the suggestion made by Casal, that the positive and the negative theses may refer to two different thresholds altogether (2007). Before doing so however, it is worth highlighting the ambiguity of the distinction between the positive and the negative theses. In one version, the positive thesis says that there is level of well-being $\mathrm{T}$, such that it is especially morally important that people reach it. The negative thesis then says that above $\mathrm{T}$, no further principles of distributive justice apply. ${ }^{21}$ In a second version however, the positive thesis says that there is a level of well-being $\mathrm{P}$, such that it is especially morally important that people reach it, while the negative thesis claims that there is a level of well-being $\mathrm{N}$ such that above $\mathrm{N}$, no further distributive principles apply. The crucial difference between these two versions is that the first presupposes that the two theses refer to the same threshold (T), whereas the second refers to two thresholds ( $\mathrm{P}$ and $\mathrm{N}$, respectively) which may or may not coincide. I will claim that the second version is more plausible.

Suppose that some rendering of both the positive and the negative theses (as understood by the second version) are true (as I believe they are):

Pos: There is a level of well-being $\mathrm{P}$ such that it is especially morally important that people reach it.

Neg: There is a level of well-being $\mathrm{N}$ such that above it, justice concerns do not arise, and such that those below has absolute priority over those above it.

The question now is why we would think that these two theses refer to the same threshold? (Casal 2007: 317) After all, they are two distinct theses, and it is not clear that they are linked in a way that would make us suspect that they should yield the exact same result (in terms of thresholds). Moreover, it is hard to see why it would be problematic if they did refer to two different thresholds, and why this should be a worry for sufficientarianism as a theory of distributive justice (See Casal 2007: 317).

The practical implications of such a view, and perhaps also its plausibility and relevance, would to some extent depend on the size of the gap between the two thresholds defined by the positive and negative theses, respectively. The larger the gap, supposedly, the less of a difference there will be between sufficientarianism and other distributive theories. That said, my own view is that if there is such a gap, it is not very wide. In any case, to the extent that there is a gap, sufficientarians need

\footnotetext{
${ }^{21}$ Casal writes that "The positive thesis stresses the importance of people living above a certain threshold, free from deprivation. The negative thesis denies the relevance of certain additional distributive requirements (Casal 2007: 297-298, emphases in original)." As noted, the negative thesis also, and importantly, marks the point at which those below has absolute priority over those above.
} 
to consider, among other things, how to think about distribution within the space between the thresholds. The two thresholds, moreover, can in principle be placed in a wide variety of ways. Consider first the possibility that the gap is relatively small ${ }^{22}$ :

As noted, the upper threshold is defined as the point at which distributive concerns disappear, and at which those below it gain absolute priority over those above it. If so, one would expect that level to be quite high, compared to the level of a good life. In Fig. 1 it seems that the two thresholds are too close to appropriately align with our intuitions about what constitutes a good life, and at what level absolute priority sets in. ${ }^{23}$ In addition, the closer the thresholds are, the more similar they will be to a single threshold. Thus the closer the thresholds, the harder it will be to fend off Casal's and Arneson's objection. Presumably, if it is hard to define a threshold such that it is especially important that people reach it, and such that above it, justice concerns do not arise at all, then it might be almost as hard to conceive of two thresholds such that it is especially important that people reach the first, and such that above the second, justice concerns do not arise at all, if these two thresholds are very close.

Apart from that, it is clear that even if the gap between the thresholds is narrow, we will have to consider what distributive principle(s) to apply within the gap. Consider next the possibility that the gap is relatively wide (Fig. 2):

On this picture, it seems that the lower threshold is placed too low, and the highest threshold too high. ${ }^{24}$ Intuitively, at least, the lower threshold looks more like a life where, say, basic needs are just met, than a life that is good. The highest threshold, on the other hand, seems too high, in light of potential distributive conflicts below it. If the threshold is that high, it is reasonable to think that people just below it have a very high level of welfare. In that case, it is hard to see, at least from a sufficientarian point of view, that many small claims at that level can outweigh fewer large claims much further below (I return to problems of aggregation in the next section).

Moreover, if this is how the thresholds are placed, well-being discrepancies in the gap are all the more relevant. It will be vital to figure out which (secondary) principle(s) to apply between the two thresholds. I assume that egalitarianism or prioritarianism will be the most likely candidates (and prioritarianism more so than egalitarianism (see below)). However that may be, in my view the most plausible scenario is that the gap is medium-sized (Fig. 3).

It is as indicated impossible to map the two theses directly and precisely onto a diagram, but it seems reasonable that 'a good life,' as outlined above, points to a relatively high lower threshold, that well-being increases matter (decreasingly) for quite a while, and the level at which they stop mattering altogether is a fair

\footnotetext{
${ }^{22}$ In the figures, the red line signifies the threshold defined in light of the positive thesis, and the blue line signifies the threshold defined in light of the negative thesis. Note that the figures provided here in no way exhaust the possibilities.

23 This will of course depend on one's view of what constitutes a good life, as well as on one's views about absolute priority.

24 Judgments such as these are of course based on intuitions about how high the level of a good life is compared to a life that is maximally good, or a life that is just barely worth living. There is no precision here, but I assume that most readers either share my intuitions here, or substitute with their own.
} 


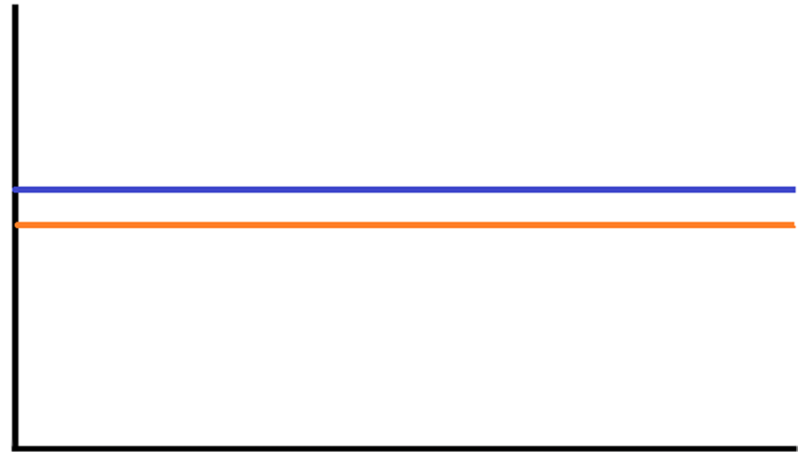

Fig. 1 Narrow gap

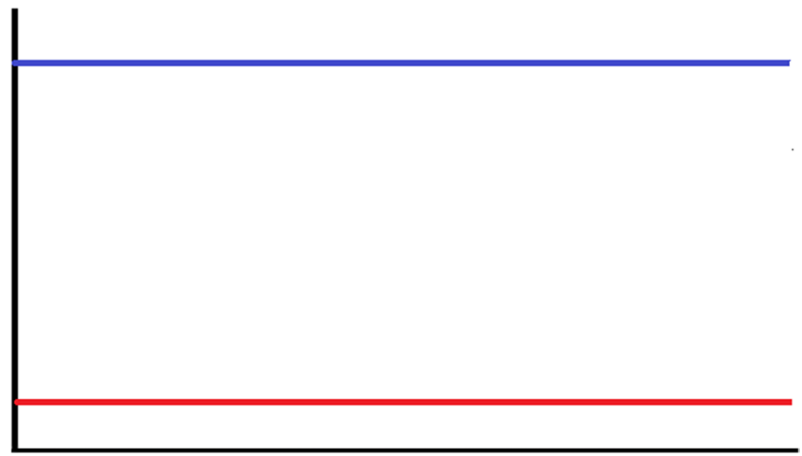

Fig. 2 Wide gap

bit higher. Importantly, however, the higher threshold is not so high as to make it implausible that that those just below it can still have plausible claims in distributive conflicts with individuals at lower levels.

Still, there might be many ways of specifying such a view. I present my favored specification in the next section.

\section{How to Distribute Below and Between the Thresholds?}

In cases where the thresholds do not coincide, at least four questions of distribution will arise. The first pertains to the distribution between individuals below the lower threshold. The second concerns the extent to which those below the lower threshold should be prioritized over those in the gap. The third concerns distribution between 


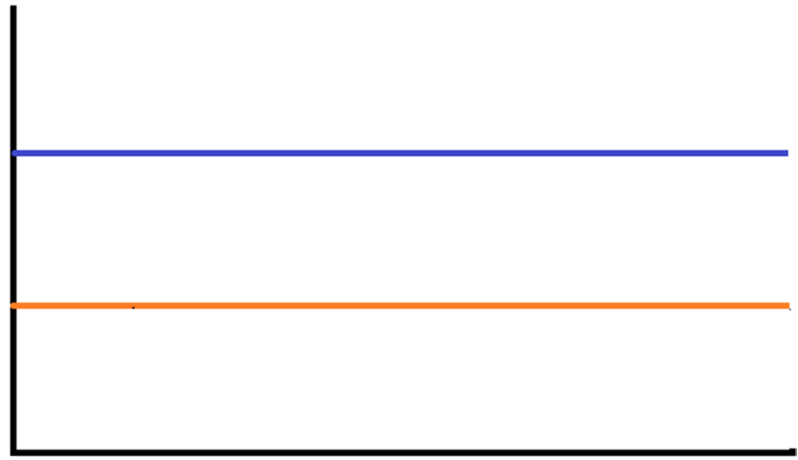

Fig. 3 Medium gap

individuals in the gap, and the fourth concerns the extent to which those in the gap should be prioritized over those above the higher threshold. ${ }^{25}$

With regard to the first question, it seems most plausible to let a prioritarian reasoning guide distribution below the lower threshold. This threshold is as noted located at the level of a good life. If, as I argued above, it is bad that some people do not have good lives, it is arguably worse the farther they are from having such good lives. In addition, it is reasonable to say that it is worse the more people who are insufficiently well off (or do not have good lives). It seems very implausible to be indifferent between a case in which one person is badly off and a case in which a million people are as badly off. Thus, we can say that shortfalls from the lower threshold are morally weighted such that they matter more the greater they are, and more the more people that experience such shortfalls. In other words, it is worse the further a person is from having a good life, and worse the more people who do not have good lives. This suggests that a negative and limited form of prioritarianism should guide distribution below the lower threshold. ${ }^{26}$

It is worth noting that standard (weighted) prioritarianism (Holtug 2010), as well as shift sufficientarianism (Shields 2016) (at least on some interpretations) value benefits (well-being) positively, and more positively the lower the level of the recipient. As Holtug (2010) realizes, this means that prioritarianism (and I would add, at least some forms of shift sufficientarianism) would rank the following outcomes like this (each number refers to an individual, and the higher the number, the higher the individual's well-being level): A $(12,12)<\mathrm{B}(6,6,6,6)<\mathrm{C}(4,4,4,4,4,4)<\mathrm{D}(3$,

\footnotetext{
${ }^{25}$ Possibly, a fifth question concerns whether to opt for utilitarianism above the upper threshold (Crisp 2003). I leave this possibility aside here.

${ }^{26}$ See Holtug (2010) for a form of (non-negative) prioritarianism. See also Huseby (2010) and Crisp (2003). This way of prioritizing below the lower threshold contrasts with the so-called headcount claim (Frankfurt 1987; Shields 2012), according to which we should maximize the number people who are sufficiently well off rather than minimize the extent of insufficiency. I agree with Casal (2007) that the headcount claim is implausible.
} 
$3,3,3,3,3,3,3)<\mathrm{E}(1,1,1,1,1,1,1,1,1,1,1,1,1,1,1,1,1,1,1,1,1,1,1,1){ }^{27}$ Suppose for the sake of the argument that a good life requires a well-being level of 4. If so, my proposed version of the positive thesis and its corresponding threshold would imply that nothing is wrong in $\mathrm{A}, \mathrm{B}$, and $\mathrm{C}$, but that quite a lot is bad in $\mathrm{D}$ and even more is bad in E. This seems to me a perfectly plausible evaluation. Even if a person has a life that consists, on balance, of more pleasure than pain, such that her life is worth living, if only barely, there is something regrettable about that life if it is not a good life. ${ }^{28}$ And many more such lives do not make things aggregately better and better, and cannot outweigh fewer lives that are good.

As indicated above, this form of sufficientarianism opens up for some aggregation problems. Tiny gains to many almost sufficiently well off people might at some point outweigh large gains to a few severely badly off people. In some instances, this will be counterintuitive. It is worth keeping in mind, however, that denying this form of aggregation outright would have severe consequences as well. Such a denial would mean that in some situations at least, all resources should go to the worst off individual. This would amount to leximin prioritarianism and would be very implausible. Since it is always possible that some of the worse off are very inefficient converters of resources into well-being, there is an ever present risk that giving absolute priority to them will quickly lead to resource drainage, such that all available resources are directed towards a few unfortunate individuals. This is an implication that seems at least as problematic as the aggregation problems associated with (unconstrained) prioritarianism and utilitarianism. Allowing (weighted) prioritization below the threshold is a way of striking a reasonable balance between wasteful absolutism and runaway aggregation (see above).

What about the second question? How strongly should we prioritize those below the lower threshold over those in the gap? Unless some priority is given, the lower threshold appears to lose its significance. Beyond that, alternatives range, in principle, from very weak to absolute priority. Recall, however, that the lower threshold matters quite a lot to sufficientarians. It points to a level of a good life, and it is particularly important that individuals reach it. This indicates a priority leaning towards

\footnotetext{
${ }^{27}$ This is a version of the 'repugnant conclusion' (Parfit 1984). Holtug (2010) dubs it the 'super repugnant conclusion' because valuing well-being more at lower levels leads to a sort of prioritarian wellbeing race to the bottom. Utilitarianism, of course, would be indifferent between all four outcomes. While I think that this is a relevant aspect of prioritarianism to point out, it is of course risky to wade into population ethics. My own proposal share some structural features with critical level utilitarianism (Blackorby et al. 1997). According to Arrhenius (forthcoming), critical level utilitarianism implies the 'sadistic conclusion'. On the other hand, utilitarianism and prioritarianism imply the 'very repugnant conclusion' (in addition to the repugnant and [for prioritarianism] the super repugnant conclusions). Thus, one might wonder how much weigh to put on the super repugnant conclusion in isolation. I think, however, the general conundrum of population ethics notwithstanding, that the small scale version of the super repugnant conclusion discussed in the text, points to an important and central feature of prioritarianism that is worth emphasizing and contrasting with my suggested sufficientarian view.

${ }^{28}$ This is also true of those who cannot be brought to the threshold, for instance due to severe disabilities or mental illness. It is worth noting, however, that there are many factors that can lead to a life not being good in the relevant sense, and that good lives certainly can be lives with disabilities and illnesses. Further, while it is morally regrettable that some person does not have a good life, this does not (of course) mean that people with less than good lives are less morally valuable than others.
} 
the strong end of the spectrum. The priority should, however, not be absolute, for two reasons. First, even if it is especially important that individuals are sufficiently well off, or that they have lives that are good, it could be argued that a few small shortfalls from the lower threshold cannot always outweigh losses, no matter how big, to individuals in the gap. ${ }^{29}$ Second, here too a problem of resource drainage might arise. Even if most people have lives that are good, a few badly off inefficient converters of resources to well-being might claim all resources above the threshold, if we accord absolute priority to those below it (See Widerquist 2010). Thus, those below the lower threshold should have a very strong, but not absolute priority over those in the gap.

It is hard to be completely precise about this priority, but for a rough illustration, suppose that the prioritarian function below the lower threshold is linear, and that the moral value of providing one well-being unit to a person with a neutral wellbeing level counts for $1 .^{30}$ The next counts for 0.9 , and so on. The last unit, the one that brings a person to the level of a good life, counts for 0.1 . This would provide a pretty straightforward aggregation scheme below the threshold.

Above the threshold, well-being matters, but far less than below. This can again be illustrated by assuming that the first well-being unit above the level of a good life counts for 0.01 . The next counts for 0.009 , and so on. The last unit, the unit that brings a person to the upper threshold, above which well-being does not matter morally, counts for 0.001. Even if simplified, this should indicate the kind of strong priority accorded to those below the lower threshold over those above, and what aggregation could look like. This priority is in many ways similar to the 'shift' in shift sufficientarianism, since there is a discontinuity in the way well-being increases are valued, above the threshold that corresponds to the positive thesis. ${ }^{31}$

This also goes a long way towards answering the third question. The distribution between the thresholds will on this view be organized in a prioritarian fashion. An alternative could be to apply egalitarianism in the gap. One consideration against egalitarianism in this particular context, is that it might, under some circumstances, lead to an unattractive form of 'layering' of well-being levels. If we assume that half the population is just below the threshold, and half above, to varying degrees, and that those below are such inefficient converters of resources to well-being that only distribution within the gap is an option, equality would lead to one layer of better off individuals in the gap, and one layer of worse off individuals just below the threshold. ${ }^{32}$ This is not an absurd implication, but it seems that prioritarian reasoning is a better fit with the sufficientarian view I propose here.

\footnotetext{
${ }^{29}$ Depending on the size of the gap, the relevant loss to each individual (in the gap) may not be great in itself. However, the loss can be great if very many (in the gap) stand to lose well-being to some significant extent.

${ }^{30}$ This is a simplification also because shortfalls from the lower threshold count as negative. So providing a well-being unit to someone with a neutral level would actually reduce the negative value by 1 , and not add a positive value of 1 .

31 I will nevertheless avoid the term shift sufficientarianism. First, because I think my proposal differs in important respects from shift sufficientarianism, and because all prioritarian functions comprise (many) shifts, in the sense that the value of well-being diminishes, the better off the recipients are.

32 Thanks to Göran Duus-Otterström for pointing this out.
} 
In addition, the well-known levelling down objection to egalitarianism would give some reason to prefer prioritarianism as well (Parfit 1997). To be sure, the consequences of levelling down would be constrained by the lower threshold, such that even after levelling down, everyone involved would still have good lives. Even so, there could be cases in which many people with very good lives would have to be levelled down to equal a few with lives that were just barely good, just for the sake of achieving equality. This seems unnecessarily wasteful.

The fourth question concerns the degree of priority we should assign to those below the higher threshold over those above it. As I have already suggested, the higher threshold will have to take into account Arneson's and Casal's suggestion that that this threshold will be more plausible the higher it is. However, aggregation problems pushes the threshold downwards. It is more plausible to let small gains to many better off individuals outweigh severe losses to fewer worse off individuals, the worse off the better off are, in absolute terms. There is, as noted above, an unavoidable trade-off to be made here. These considerations, along with reflection upon what counts as a 'good' life, are some of the reasons why I think it likely that the gap will turn out to be at most medium-sized. This might appear unsatisfactory, but the horns of the dilemma that we are trying to avoid are indeed sharp. It sounds wrong to let trivial goods to extremely well off people outweigh, say, severe pain and suffering to a badly off person, and it sounds wrong to give the worst off absolute priority, thus draining resources that might otherwise benefit scores of other people. By placing the upper threshold a fair distance above the level of a good life, and a fair distance below the level of a maximally good life, the proposed view avoids both these unpleasant results (though not completely). Thus the upper threshold is placed such that there is a medium-sized gap between the thresholds. Above this upper threshold, further distributive principles do not apply, and more importantly, individuals below this threshold have absolute priority over those above.

\section{Other Sufficientarian Views}

Given the range of available alternative accounts in the literature, and given that some of these accounts may resemble the view presented here, it is worthwhile explaining briefly what my proposal adds to sufficientarian theory. Consider first Shields' sufficientarian account. He argues that sufficientarians can make do with a combination of the positive thesis and the 'shift thesis':

Once people have secured enough there is a discontinuity in the rate of change of the marginal weight of our reasons to benefit them further (Shields 2012: 108; Shields 2016: 30).

This view denies the negative thesis. Rather, benefits to the sufficiently well off matter somewhat, but benefits to those below the threshold matter disproportionately 
more. ${ }^{33}$ This view is in some respects similar to prioritarianism. It differs from prioritarianism, however, in that the moral value of well-being does not decrease continuously the better off the recipient is. ${ }^{34}$ Rather, there is a break, or a shift, at the sufficiency threshold.

My view might appear quite similar to the shift thesis. There are however, two important differences. First, my view accepts the negative thesis, whereas Shields' does not. As indicated, the negative thesis is controversial and there will be disagreement about whether accepting it constitutes an asset or a liability. In my view, however, the negative thesis is important in order to avoid the forms of aggregation that lets small benefits to the very well off outweigh great losses to the very badly off.

One might object here, that whether or not the shift thesis allows such problematic aggregation depends on the details of the shift. A shift sufficientarian might argue, for instance, that the priority to those below the lower threshold is so strong as to practically ban these forms of aggregation. In reply, note that problematic aggregation remains a possibility so long as the priority to those below the lower threshold is not absolute.

This possibility, however, indicates the second difference between my view and the shift thesis. The latter is a general framework. The discontinuity in the rate of change of the importance of further benefits is not specified. This does not make the view implausible, but it does reveal the need for more specific accounts. Further, the shift thesis does not say how much less benefits matter above the threshold. Nor does it say clearly how to prioritize between those above the threshold. It is clear then, that my proposal is not equivalent to the shift thesis. ${ }^{35}$

On Benbaji's view, sufficientarianism comprises multiple levels. The various levels, moreover, refer to thresholds that are such that it is especially important that people reach it. Whenever a person is below a threshold, she has priority (but not absolute priority) over anyone above it. However, differences in well-being between thresholds are completely unimportant (Benbaji 2006: 343). Further, Benbaji seems to deny the negative thesis. ${ }^{36}$ As should be clear, this view is different from the one proposed here. My two thresholds are tied to the two theses, which Benbaji's thresholds are not. In addition, I accept the negative threshold whereas Benbaji does not.

According to Axelsen and Nielsen's capability-inspired sufficientarianism, justice requires 'freedom from duress.' The vital term 'duress' refers to a “...situation in which one is under significant pressure in central areas of human life, pressure

\footnotetext{
33 This is not, then, a sufficiency-constrained form of prioritarianism according to which securing sufficiency has absolute priority over benefits to those who are already sufficiently well off. At least, this will be only one possible form of shift-sufficientarianism.

34 See for instance Holtug (2010: 133).

35 A more serious problem, noted above, is that, since shift-sufficientarianism is positively phrased, it is susceptible to versions of the repugnant conclusion (Parfit 1984), the super repugnant conclusion (Holtug 2010), and the very repugnant conclusion (Arrhenius 2003). See also Huseby (2012).

36 Benbaji (2006: 347, note 45) suggests that a benefit that will bring a well off person to 'perfection' might outweight smaller benefits to people below (some) threshold.
} 
that would impede any normal human being's ability to succeed in a similar situation. Freedom from duress ... is a state of freedom from any such pressure, and this ... denotes the situation in which one has enough." Axelsen and Nielsen (2015: 406). Emphasis in original. This view also involves several thresholds, pertaining to the different central areas of human life. These multiple thresholds, however, do not refer to different levels on one aggregate scale. Rather, they point to the level of sufficiency in different dimensions of human life (Axelsen and Nielsen 2015: 407), which is different from the two thresholds that I have defended above.

Lastly, consider a view that I have defended myself earlier, according to which there are two thresholds, one referring to the level of subjective contentment, and one referring to the satisfaction of basic needs. The lower threshold, on this view, does not refer to the positive thesis. It just emphasizes priority to the very badly off. The higher threshold, moreover, is intended to capture both the positive and the negative thesis (Huseby 2010). It is especially important that people reach this threshold, and further distributive concerns are irrelevant above it. The view proposed here, again, is clearly different from this, because the negative and positive theses are seen as referring to two distinct thresholds.

One might worry that my view seems implausibly complex. I think, however that it is hard to decide in the abstract how complex a distributive theory can plausibly be. While I do not deny that simplicity is, all else equal, a virtue, it is very hard to say when everything else is equal. Further, the complexity of the view, such as it is, falls out of two very reasonable claims, namely that there is a level of well-being such that it is very important that people reach it, and that there is a level of wellbeing such that distributive concerns disappear above it. In my view, the plausibility of these claims outweighs those concerns that may arise from complexity.

\section{Conclusion}

It appears then, that the threshold-question can be adequately addressed. I have in this paper proposed a solution, according to which the positive and negative sufficiency theses refer to distinct thresholds. I have further argued that this proposal is plausible and distinct from other accounts in the literature. If I am right that both the negative and the positive theses are reasonable and point to distinct thresholds, we have reason to (still) think that sufficiency is indeed a promising conception of distributive justice. The view suggested here, moreover, will be appealing to those who think (a) that there is a level such that it is especially important that people reach it, (b) that distributive concerns might be relevant above this threshold, but (c) that there is nevertheless a level such that distributive concerns do not matter at all, and below which people have absolute priority over those above. 
Acknowledgements Earlier versions of this paper was presented at workshops and conferences at the University of Oslo (2019), the Institute for Future Studies in Stockholm (2019), Pompeu Fabra University in Barcelona (2018), and the University of Gothenburg (2016). I am grateful for all the helpful comments I received on these occasions, and I would in particular like to thank Marcus Agnfors, Kim Angell, Gustaf Arrhenius, David Axelsen, Yitzhak Benbaji, Paula Casal. Alexandra Couto, Henrik D. Kugelberg, Göran Duus-Otterström, Jakob Elster, Hege C. Finholt, Marc Fleurbaey, Anders Herlitz, Fredrik D. Hjorthen, Magnus Hoel, Andreas H. Hvidsten, Sigurd Lindstad, Sune Lægaard, Ole Martin Moen, Lasse Nielsen, Serena Olsaretti, Ed Page, Jørgen Pedersen, Wlodek Rabinowicz, Shlomi Segall, Liam Shields, Frej Klem Thomsen, Jens Jørund Tyssedal, Andrew Williams, Chris Zhang, as well as the anonymous reviewers for this journal. Open Access funding provided by Oslo University \& Oslo University Hospital.

Open Access This article is licensed under a Creative Commons Attribution 4.0 International License, which permits use, sharing, adaptation, distribution and reproduction in any medium or format, as long as you give appropriate credit to the original author(s) and the source, provide a link to the Creative Commons licence, and indicate if changes were made. The images or other third party material in this article are included in the article's Creative Commons licence, unless indicated otherwise in a credit line to the material. If material is not included in the article's Creative Commons licence and your intended use is not permitted by statutory regulation or exceeds the permitted use, you will need to obtain permission directly from the copyright holder. To view a copy of this licence, visit http://creativecommons.org/licen ses/by/4.0/.

\section{References}

Anderson, Elizabeth. 1999. What is the point of equality? Ethics 109: 287-337.

Arneson, Richard. 2005. Distributive justice and basic capability equality: 'Good Enough' is not good enough. In Capabilities equality: basic issues and problems, ed. A. Kaufman, 17-43. London: Routledge.

Arrhenius, Gustaf, Population ethics - the challenge of future generations Oxford: Oxford University Press (forthcoming).

Arrhenius, Gustaf, The very repugnant conclusion, in K. Segerberg and R. Sliwinski (eds.) Logic, law, morality: thirteen essays in practical philosophy in honour of Lennart Aquist, Uppsala philosophical studies (Uppsala: Department of Philosophy, Uppsala University, 2003), pp. 167-80.

Axelsen, David, and Lasse Nielsen. 2015. Sufficiency as freedom from duress. The Journal of Political Philosophy 23: 406-426.

Benbaji, Yitzhak. 2005. The doctrine of sufficiency: a defenc. Utilitas 17: 310-332.

Benbaji, Yitzhak. 2006. Sufficiency or priority? European Journal of Philosophy 14: 327-348.

Blackorby, Charles, Walter Bossert, and David Donaldson. 1997. Critical level utilitarianism and the population-ethics dilemma. Economics and Philosophy 13: 197-230.

Casal, Paula. 2007. Why sufficiency is not enough. Ethics 117: 296-336.

Crisp, Roger. 2003. Equality, priority, and compassion. Ethics 113: 745-763.

Dworkin, Ronald. 2000. Sovereign virtue-the theory and practice of equality. Cambridge: Harvard University Press.

Frankfurt, Harry. 1987. Equality as a moral ideal. Ethics 98: 21-43.

Holtug, Nils. 2010. Persons, interests, and justice. Oxford: Oxford University Press.

Hupfer, Elizabeth C. 2019. Distributing welfare and resources. Journal of Philosophical Research 44: 273-292.

Huseby, Robert. 2010. Sufficiency—restated and defended. The Journal of Political Philosophy 18: $178-197$.

Huseby, Robert. 2012. Sufficiency and population ethics. Ethical Perspectives 19: 187-206.

Huseby, Robert. 2019. Sufficientariansm. In Oxford research encyclopedia of politics, ed. W.R. Thompson. New York: Oxford University Press.

Nielsen, Lasse. 2016. Sufficiency grounded as sufficiently free: a reply to Shlomi Segall. Journal of Applied Philosophy 33: 202-216.

Orr, Shepley, Sufficiency of resources and political morality (manuscript).

Parfit, Derek. 1984. Reasons and persons. Oxford: Oxford University Press. 
Parfit, Derek. 1997. Equality and priority. Ratio 10: 202-221.

Raz, Joseph. 1986. The morality of freedom. Oxford: Clarendon Press.

Robeyns, Ingrid. 2015. Having too much. In NOMOS LVI: welath. Yearbook of the American Society for Political and Legal Philosophy, ed. J. Knight and M. Schwartsberg, 1-44. New York: New York University Press.

Segall, Shlomi. 2016. What is the point of sufficiency. Journal of Applied Philosophy 33: 36-52.

Shields, Liam. 2012. The prospects for sufficientarianism. Utilitas 24: 101-117.

Shields, Liam. 2016. Just Enough: sufficiency as a demand of justice. Edinburgh: Edinburgh University Press.

Widerquist, Karl. 2010. How the sufficiency minimum becomes a social maximum. Utilitas 22: 474-480.

Publisher's Note Springer Nature remains neutral with regard to jurisdictional claims in published maps and institutional affiliations. 